\title{
ЧАСТИ СУТОК В ИСПАНСКОЙ ЛИНГВОКУЛЬТУРЕ: СОСТАВ И ЭВОЛЮЦИЯ ПОНЯТИЯ MAÑANA
}

\section{PARTS OF THE DAY IN SPANISH LINGUOCULTURE: COMPOSITION AND EVOLUTION OF THE CONCEPT MAÑANA}

\section{E. Popova}

Summary: The article deals with the semantic peculiarities of the Spanish lexeme la mañana, which describes a certain part of the day, with their development and actualization in different contexts. Based on the material of dictionaries and discourse, the article reveals culturallybound features of the Spanish temporal picture of the world. Particular attention is paid to the Spanish speakers' perception of certain periods within the daily circle. The purpose of the analysis is to prevent possible communication difficulties associated with mastering Spanish vocabulary of time by native speakers of the Russian language.

Keywords: parts of the day, lexical unit, lexical meaning, meaning component, actualization.

\section{Введение}

В испанском языке лексема mañana может выступать как в качестве существительного, так и в качестве наречия, причем существительное будет иметь разные значения, в зависимости от рода. La mañana, в женском роде, приблизительно соответствует русской лексической единице (далее - ЛЕ) «утро», a el mañana, в мужском, обозначает ближайшее будущее (в оппозиции к ЛЕ el futuro со значениями отдаленного будущего и будущего времени как грамматической категории). Наречие mañana, исходя из словарного значения, примерно соответствует русскому наречию «завтра», однако имеет и прагмасемантические нюансы, обусловленные испанской культурой и не зафиксированные в словарях (в частности значения «неизвестно, когда», «никогда и ни за что»).

Предметом исследования в настоящей статье выступает понятие la mañana, связанное с репрезентацией определенной части суток. Период, обозначаемый испанцами с помощью указанной лексемы, на русский язык переводится как «утро», однако объем значений двух понятий совпадает далеко не полностью, что связано с особенностями конкретных культур и восприятия соответствующих концептов их носителями. Подобные исследования представляются актуальными, поскольку их результаты способствуют более глубокому пониманию иной культуры и предупреждению возможных коммуникативных трудностей, связанных с использованием не носителями

\author{
Попова Евгения Андреевна \\ к.филол.н., доцент, ФГБОУ ВО «Московский \\ государственный лингвистический университет» \\ o-genia@yandex.ru
}

Аннотация: Статья посвящена особенностям семантики испанской лексемы la mañana, описывающей определенную часть суток, их развития актуализации в разных контекстах. На материале словаря и дискурса выявляются культурно-специфичные черты темпоральной картины мира носителей испанского языка. Особое внимание уделяется описанию восприятия носителями испанского языка определенных периодов в пределах суточного круга. Целью анализа является предупреждение возможных коммуникативных трудностей, связанных с усвоением испанской лексики времени носителями русского языка.

Ключевые слова: части суток, лексическая единица, лексическое значение, компонент значения, актуализация.

испанского языка его темпоральной лексики.

Цель статьи - выявление лингвокультурологических особенностей испанского концепта la mañana ( $\approx$ утро) и причин, по которым он считается самым «размытым» для понимания иностранцами среди частей суточного круга (см. [Корнилов 2011; Попова 2015, 2020]). Материалом для языкового анализа в синхроническом и диахроническом ракурсах послужили толковые, этимологические и переводные словари испанского языка. Примеры актуализации языковых единиц взяты из ходужественных и публицистических источников, отобранных из Корпуса CREA Испанской Королевской Академии.

\section{Гранишы испанского «утра»}

Согласно большинству словарных определений, в значении понятия la mañana сочетаются компоненты «присутствие солнечного света» (presencia de luz solar) и «темпоральность» (temporalidad). Исторически mañana происходит из вульгарной латыни: изначально *maneana - это прилагательное женского рода, сокращение от словосочетания *maneana hora - «ранний час», в свою очередь образованного от латинского *mane «утром». Значение «присутствие солнечного света в первые мгновения дня» (la presencia de la luz solar en los primeros momentos del día) появляется у данной лексической единицы (далее - ЛЕ) в XII-XIII веках [Diccionario etimológico...]. 
Что же происходит с изучаемым понятием в современном испанском языке? Указанное значение до сих пор фигурирует среди дефиниций авторитетных толковых словарей испанского языка. Так, словарь María Moliner определяет длительность данного периода, вопервых, от рассвета до полудня (tiempo que media desde que amanece hasta el mediodía), а во-вторых, ограничивает его первыми часы дня (суток), до восхода солнца (primeras horas del día, aun antes de salir el sol) [Moliner 2009]. B словаре Sopena первое значение полностью совпадает с толкованием №1 предыдущего источника, второе же является более широким по сравнению с тем, которое предлагает María Moliner: период времени от полуночи до полудня (espacio de tiempo desde la media noche hasta el mediodía) [Sopena 1978]. Словарь Испанской Королевской Академии RAE, повторяя в одном из значений определение №2 Sopena, в другом в качестве «нижней» границы данной части суток предлагает рассвет, а «верхней» - не просто полдень, а время обеда (parte del día comprendida entre el amanecer y el mediodía, o la hora de comer o almorzar) [DRAE].

Словоупотребление также показывает, что понимание поздней «границы» концепта mañana носителями языка не ограничивается полуднем: например, в расписании посещения музея-маяка в Сантандере находим следующую информацию: De martes a viernes: Sólo mañanas: 10:30 a 13:30 horas («ВТ-пт: только первая половина дня (букв. «утром»): с 10.30 до 13.30»); Domingos: Sólo mañanas: 11:30 a 14:30 horas («Bc: только первая половина дня (букв. «утром»): с 11.30 до 14.30»). О каком времени подумает носитель русского языка, услышав, что музей в воскресенье открыт только por la mañana? Даже более адекватный, чем «утром» перевод «в первой половине дня» будет слишком узок для периода, обозначенного в расписании, поскольку в русском языке «первая половина дня» будет ограничена полуднем или, в крайнем случае, часом после полудня.

Обед, не случайно упомянутый в словаре RAE в качестве «поздней» границы для понятия mañana, является важным культурном маркером для членения суток в испанском языке. Именно этот вид деятельности у испанцев считается одним из наиболее важных в течение дня, и по нему проходит граница между понятиями día и tarde, которые используются в приветственных клише: до обеда это buenos días (= «доброе утро»), после обеда и до вечера - buenas tardes (= «добрый день»). Важно отметить, что в приветствиях лексема mañana не используется, при том что носители испанского языка определяют данное понятие практически так же, как и словарь RAE, который оказывается наиболее близок к его повседневному восприятию: время с момента, когда вы обычно просыпаетесь, до обеда - 3 часов дня (desde que te despiertas normalmente hasta la hora de comer - 15 h.) [Wordreference].
Что касается ранней границы изучаемого периода, для обозначения точного часового времени mañana, как правило, используется, начиная лишь с 5-6 часов утра (a las 5 de la mañana, a las 6 de la mañana). Реже возможно использование сочетаний las 3 / las 4 de la mañana [Martín, Pérez, Ramos 2007; Moliner 2009], поскольку для периода от полуночи и до рассвета существует понятие madrugada, не имеющее точного эквивалента в русском языке: la 1 de la madrugada - час ночи, a las 4 de la madrugada - уже 4 часа утра.

\section{Mañana-1 и mañana-2: источники противоречий}

Чтобы понять причины описанных временны́х «накладок», попытаемся проанализировать историю развития сем, заложенных в понятие mañana. В Средние века в основе понятия находилась простая бинарная оппозиция - наличие / отсутствие солнечного света. На Рисунке 1 mañana представляет собой часть светового дня и противопоставляется понятию посhе как темному времени суток.

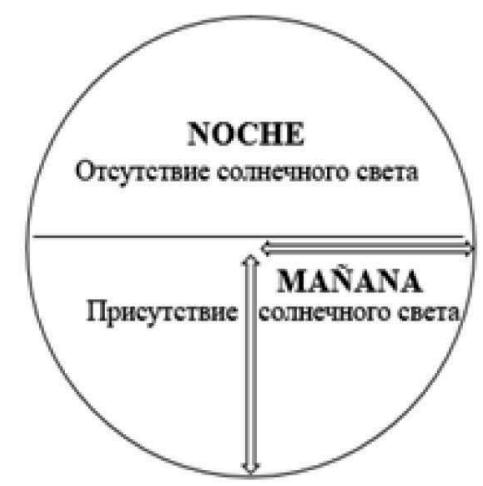

Puc. 1. Oбобиеняое предстаетение оппозичи NOCHE / MANANA nо принуру натичи / отсутстей солнечного света

K XVII веку лексема mañana уже используется для обозначения точного часового времени, в результате чего постепенно происходит вытеснение из употребления в указанном значении понятия día ( $\approx$ день), а в семантике понятия mañana развивается компонент темпоральности (*las 10 del día $\rightarrow$ las 10 de la mañana - «10 часов утра»). Вместе с тем mañana начинает расширять границы значения, пересекаясь с семой «время отсутствия солнечного света»: в XVII веке появляются конструкции las 4 de la mañana и las 5 de la mañana (см. Рис. 2).

Как отмечают историки романских языков, предпосылки для такого расширения значения ЛЕ mañana зарождаются еще в XV веке, когда числовое использование времени, мотивированное, отделением светского, обывательского его восприятия от эсхатологического и космологического понимания, характерного для Средневековья. В этот период начинается трехчастное оформление суток в языке с временным интервалом 8 
часов (mañana - tarde - noche), а для обозначения суток целиком актуализируется лексема día [Matoré 1983].

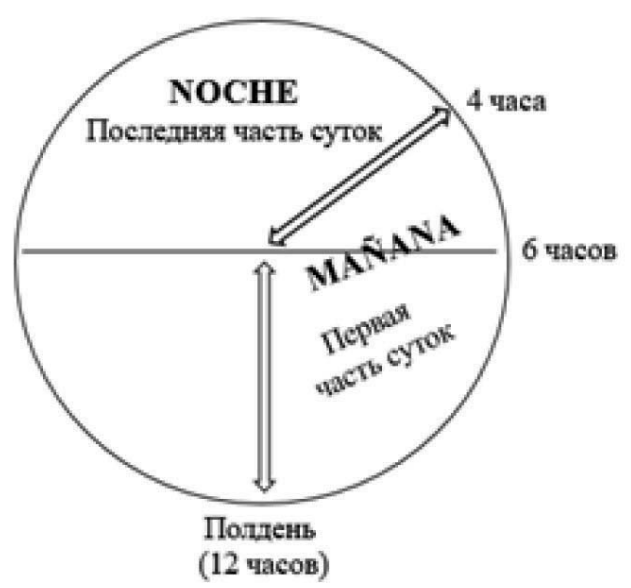

Puc. 2. Расиирение значения монцепта MANANA, опход семы норисутствие солнечного свемам на еторой план

Результаты описанной эволюции в XIX веке закрепляются в лексикографических источниках. Так, словарь Королевской Академии RAE в издании 1783 определяет понятие mañana как «время, которое проходит от восхода солнца до полудня» (tiempo que transcurre desde que amanece hasta el mediodía), а уже в издании 1869 года появляется следующее дополнение: «Иногда [данное слово] используют для обозначения периода от полуночи до полудня; так, например, можно сказать: в два или три часа утра» (Se usa algunas veces por el espacio de tiempo desde la medianoche hasta el mediodía; y así se dice: a las dos o a las tres de la mañana) [DRAE]. Именно с начала XIX века как в литературных произведениях, так и в периодической печати все чаще встречаются подобные примеры:

- A la una de la mañana, viendo que tú no venías, me fui a la cama («В час ночи (букв. в час утра), видя, что ты не возвращаешься, я пошел спать») [Baroja P., Zalacaín el aventurero - CREA].

- Año 1646, domingo, a 29 de abril, a las dos de la mañana se tañó la campana («В 1646 году, в воскресенье, 29 апреля, в два часа ночи (букв. в два часа утра) зазвонил колокол») [Feijoo B., Teatro crítico universal - CREA].

- (...) a las 3 de la mañana del 19, en que se estaba formando la tropa para emprender la marcha («... в 3 часа утра 19-го числа, когда формировалось войско для выступления») [El Correo de Tenerife 8.09.1808 - CREA].

Описанные значения (для удобства в дальнейшем мы будем использовать их, называя mañana-1 и mañana-2) имеют заметную тенденцию к семантическому расхождению, которая порождает определенные противоречия в восприятии изучаемого концепта и вызывает труд- ности в его адекватной актуализации у не носителей испанского языка.

\section{«ЕАинство и борьба противоположностей»}

Итак, к началу XX века для понятия la mañana окончательно формируются следующие значения: mañana-1 - «период времени от полуночи до полудня» (tiempo desde medianoche hasta el mediodía) и mañana-2 - «период времени, в котором присутствует солнечный свет, от восхода солнца до полудня» (tiempo iluminado por la luz solar desde que amanece hasta el mediodía). Именно значение mañana-1 используется при точном обозначении часового времени, актуализируя, в первую очередь, сему темпоральности. Получается, что mañana-1 включает как понятие mañana-2, так и понятие la madrugada - «время от полуночи до рассвета» (tiempo posterior a la medianoche y anterior al amanecer) [DRAE], в связи с чем mañana-2 кажется избыточным.

Тем не менее в таких сочетаниях, как, например, encendida mañana («солнечное утро»), hermosa mañana («прекрасное утро»), de mañana («на рассвете»), lucero de la mañana («утренний свет»), актуализируется сема присутствия солнечного света. Многочисленны примеры использования значения mañana-2 и в художественной литературе:

- Mi sobrino salía de mañana a buscar dinero («Мой племянник с рассветом выходил из дома на поиски заработков») [Larra M., Vuelve usted mañana y otros artículos - CREA].

- ¡Qué alegre y fresca la mañanita! / Me agarra el aire por la nariz... (Какое радостное и свежее утро! / Воздух, который я вдыхаю, охватывает меня...) [Darío R., Del trópico - CREA].

- Por la mañana, le daban chocolate con agua; por la tarde, cocido, y de noche, una sopa de ajo infame («Утром ему давали шоколад с водой, днем - жаркое, а вечером - гадкий чесночный суп») [Baroja P., Zalacaín el aventurero - CREA].

В последнем примере ЛЕ mañana-2 также актуализирована в оппозиции к другим частям суток - la tarde (здесь: день, вторая половина дня) и la noche (здесь: вечер), составляющих суточный круг.

На Рисунке 3 представлено членение суточного круга в испанском языковом сознании, где он обозначен лексемой día. Сема начала новых суток перекликается в ней со значением mañana-1. С другой стороны, día - это эквивалент светлого времени суток в противопоставлении их темному периоду - noche. Ключевой семой для данного значения выступает «присутствие солнечного света», что «роднит» его со значением тап̃ana-2. Более того, сужаясь в контексте национальных приветствий, оно полностью повторяет границы mañana-2 и актуализируется 
вместо него в период от восхода солнца и до полудня, а точнее - до фактического обеда: *buenas mañanas в качестве приветствия в испанском языке не используется.

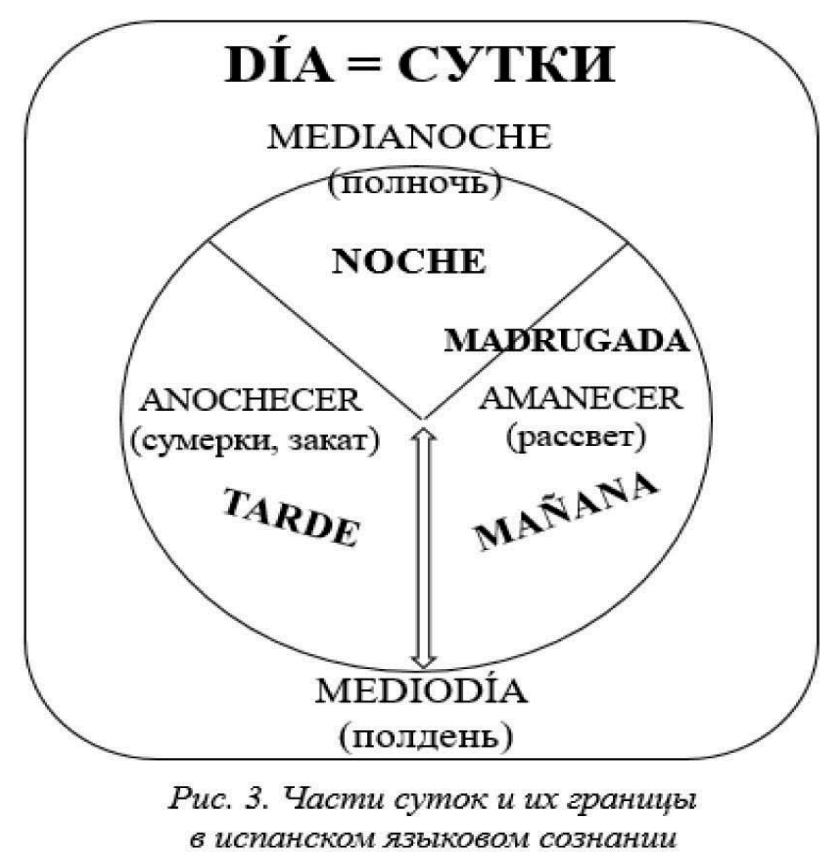

Таким образом, можно говорить о пересечении и взаимосвязи ЛЕ la mañana и el día, с одной стороны, и их «нейтрализации», с другой - в зависимости от семы, которая актуализируется в том или ином их значении. Кроме того, существует и определение для понятия la mañana, которое объединяет оба рассмотренных значения: tiempo desde la medianoche hasta el mediodía, especialmente a partir del alba («время от полуночи до полудня, особенно - период от восхода солнца») [VOX].

\section{Зак^ючение}

Из проведенного исследования можно сделать следующие выводы о семантических и культурных особенностях испанского концепта la mañana:

1. Изначально в ЛЕ la mañana главную роль играет сема присутствия солнечного света, на основании которой она противопоставляется la noche. Данная сема является релевантной для изучаемого понятия с момента его возникновения и до настоящего времени.

2. Постепенные изменения в семантике лексемы происходят начиная с XVII века, и в XIX веке в академических словарях для ЛE la mañana фиксируется значение «период времени от полуночи до полудня», в котором на первое место выходит темпоральная сема. Возникшая двойственность повлекла возникновение двух «терминов», которые мы условно обозначили mañana-1 («время от полуночи до полудня») и mañana-2 («время от восхода до полудня»), подразумевающей сему наличия естественного освещения.

3. Между ЛЕ mañana-1 и mañana-2, на первый взгляд, существует противостояние, поскольку одно из них, по сути, включает в себя второе, что вызывает трудности в восприятии изучаемого концепта. Тем не менее можно сказать, что существует довольно четкое разграничение их актуализации: mañana-1 используется для обозначения точного часового времени, тогда как mañana-2 - в описательных контекстах, особенно в оппозиции с другими частями суточного круга - la tarde, la noche u la madrugada (подчеркнем, что период mañana-1 не противопоставляется понятию la madrugada: при обозначении времени на определенном этапе - с 1 часа ночи до 4 часов утра обе ЛЕ используются параллельно).

4. Mañana-1 и mañana-2 обнаруживают и общность в семах «время» + «начало дня», хотя и различаются своей отправной точкой, в каждом случае коррелируя с одним из значений ЛЕ día. Более того, абсолютное соответствие периодов mañana-2 и día в значении «время от рассвета до полудня» позволяет ограничить использование последнего только в приветственных клише.

На наш взгляд, определение, данное понятию mañana словарем Vox и приведенное выше, максимально полно описывает его восприятие носителями испанского языка. Подчеркнем, однако, что «верхняя» граница указанного временно́го отрезка, согласно словоупотреблению, проходит не по полудню, а по времени испанского обеда (что зафиксировано в словаре DRAE), который может варьироваться с 12 до 15 часов.

\section{ЛИТЕРАТУРА}

1. Корнилов 0.А. Языковые картины мира как производные национальных менталитетов. М.: КДУ, 2011. 350 с.

2. Попова Е.А. Репрезентация суточной шкалы в русском и испанском языках: национальные особенности и современные тенденции // Современная наука: Актуальные проблемы теории и практики. Серия: Гуманитарные науки, 2020. Вып. 7. С. 148-153.

3. Попова Е.А. Семантическое поле ВРЕМЯ в межкультурной вербальной коммуникации. Дисс. ... канд. филол. наук. М., 2015. 283 с.

4. CREA: Corpus de referencia del español actual. Real academia española. URL: http://www.corpus.rae.es (дата обращения: 1.08.2021).

5. Diccionario Etimológico Castellano en Línea. URL: http://etimologias.dechile.net/ (дата обращения: 1.08.2021).

6. DRAE: Diccionario de la lengua española de la Real academia española. URL: www.dle.rae.es (дата обращения: 1.08.2021). 
7. Martín M.T., Pérez L., Ramos J. Español lengua viva-1: Libro de alumno. Madrid: Santillana Educación, S. L., 2007. 152 p.

8. Matoré G. Le temps médiéval étude lexicologique // Informatión Grammaticale, n. 9 (19), octubre, 1983. Pp. 16-20.

9. Moliner M. Diccionario de uso del español. Madrid: Gredos, 2009. $1680 \mathrm{p}$.

10. Diccionario enciclopédico Manual Sopena. Barcelona: Ed. R. Sopena S. A., 1978. Vol II. 708 p.

11. VOX: Los diccionarios que te acercan al mundo. URL: https://www.vox.es/pagina/diccionarios/ (дата обращения: 1.08.2021).

12. Wordreference: Лингвистический форум. URL: https://forum.wordreference.com/ (дата обращения: 1.08.2021).

(с) Попова Евгения Андреевна (o-genia@yandex.ru).

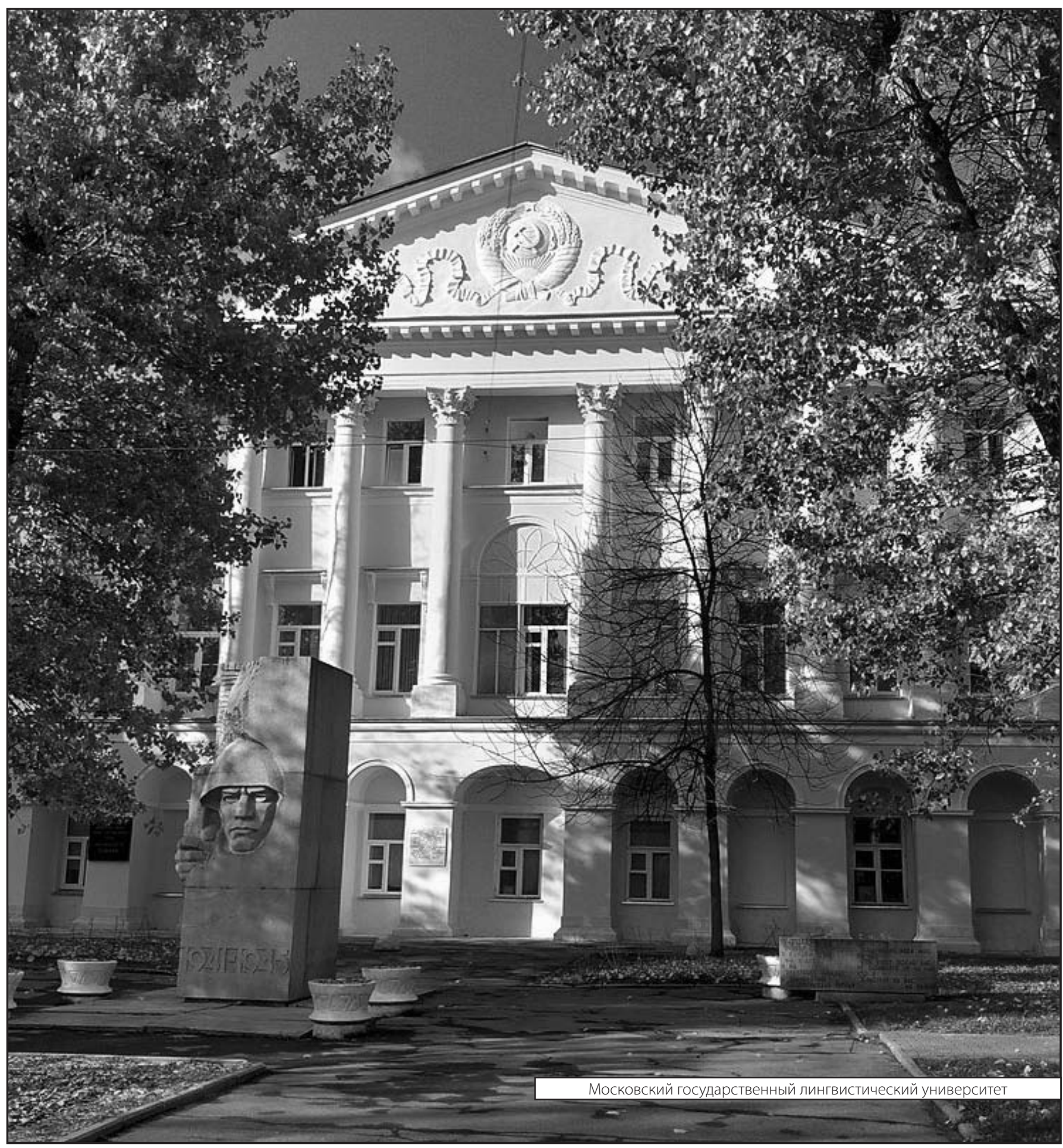

